\title{
Optimization of Design Scheme for Toll Plaza Based on M/M/C Queuing Theory and Cellular Automata Simulation Algorithm
}

\author{
Yi-Jian Liu ${ }^{1,2}$, Jian Cao ${ }^{1,2}$, Xiao-Yan Cao ${ }^{1,3}$ \& Yuan-Biao Zhang ${ }^{1,4}$ \\ ${ }^{1}$ Innovation Practice Base of Mathematical Modeling, Electrical and Information College of Jinan University, \\ Zhuhai, China \\ ${ }^{2}$ Electronic Information Science and Technology, Electrical and Information College of Jinan University, Zhuhai, \\ China \\ ${ }^{3}$ Information Security, Electrical and Information College of Jinan University, Zhuhai, China \\ 4 Key Laboratory of Product Packaging and Logistics of Guangdong Higher Education Institutes, Jinan \\ University, Zhuhai, China \\ Correspondence: Yuan-Biao Zhang, Innovation Practice Base of Mathematical Modeling, Electrical and \\ Information College of Jinan University, Zhuhai 519070, China. E-mail: zybt@jnu.edu.cn
}

Received: April 13,2017

Accepted: April 25, 2017

Online Published: April 30, 2017

doi:10.5539/mas.v11n7p1

URL: https://doi.org/10.5539/mas.v11n7p1

\begin{abstract}
As an important field in traffic control science, the research in design of toll plazas has increasingly attracted attention of scholars and society. A good design of toll plaza needs to meet a lot of conditions, such as high safety coefficient, high throughput and low cost level. In this study, we established an e valuation model of toll plaza based on cellular automata and $\mathrm{M} / \mathrm{M} / \mathrm{C}$ queuing theory applying to three aspects: safety coefficient, throughput and cost. Then, we took the Asbury Park Toll Plaza in New Jersey as an example to analyze its performance and further optimized the design of the toll plaza. Compared with the original design, the optimized toll plaza we designed is proved to be safer and preferable. Last but not least, we further analyzed the robustness of the designed toll plaza, proving that the designed toll plaza had a preferable performance in reality.
\end{abstract}

Keywords: Toll Plaza, Design Scheme, M/M/C Queuing Theory, Cellular Automata

\section{Introduction}

In modern society, with the increase of population, the traffic problem is becoming more and more serious. What's more, in the field of transportation, it is a knotty problem to solve how to improve the safety factor and ease congestion in some toll plazas. Nowadays, scholars all over the world have begun to pay attention to the traffic problems of the toll plaza, including traffic congestion, traffic accidents and poor design of the toll plaza. Therefore, more researches are needed to solve this important problem, aiming at designing a satisfactory toll plaza. At the same time, it is necessary to combine the design with the advanced technology of computer and science, such as traffic flow simulation and so on.

Aiming at the problem of optimal design of the toll plaza, many scholars have made a lot of researches on toll plaza design and traffic flow simulation algorithm. Among them, Albert E. Schaufler did a report which focused on the design factors affecting toll plazas, including traffic, location and configuration of toll plazas, as well as congestion management, operation and maintenance of the facility and so on (Schaufler, 1997). Nico M.van Dijk and Mark D. Hermans studied how to apply the queuing theory to design toll plaza, determine the type of toll collection system and the quantity of tollbooths (Van Dijk, N. M., Hermans, M. D., Teunisse, M. J. \& Schuurman, H.,1999). Perry, Ronald F, Gupta, Surendra M established a typical toll plaza simulation model based on traffic volume, average queue length, average waiting time, and tollbooths utilization. Then, they applied the method of multiple linear regression analysis to obtain the optimal toll plaza vehicle distribution scheme (Perry, R. F. \& Gupta, S. M.,2001).

In addition, many experts have also done some researches on the traffic flow simulation model. Komada and Masukura studied the traffic states and jams occurring in traffic flow on a two-lane toll highway and analyzed the effects of the density and fraction of both vehicles on traffic flow (Komada, K., Masukura, S. \& Nagatani, T., 2009). In Nan Zhang's master's thesis, he pointed out that in the research of highway toll plaza, researchers 
hadn't proposed new theoretical methods, but mostly used the two formulas in Traffic Flow Theory (Daniel, Gerlaugh, Ma Xiu, Huber \& Jiang-Huang, 1983) and Japan highway design essentials (Li,1991) based on M/M/C queuing theory (Zhang, 2015). What's more, Zhang, Wang and Hu presented a kind of cellular automaton model (NS-BCA) to analyze the mixed traffic flow of intersection (Zhang, Wang \& Hu, 2014). In Xian-Juan Kong's doctoral dissertation, she studied the traffic flow model for single and dual lanes based on cellular automata simulation (Kong,2007).

Cellular automaton, which was first proposed by Von Neumann in 1950s, was a discrete dynamical system. In 1986, Cremer and Ludwig first applied cellular automata to vehicle traffic studies (Cremer, M., \& Ludwig, J., 1986). Nowadays, the cellular automata theory of traffic flow model is more and more used in large-scale system traffic flow simulation research. Among them, the most famous models are N-S model proposed by Nagel and Schreckenberg (Nagel, K., \& Schreckenberg, M., 1992) and BML model proposed by Biham, Middleton and Levine (Biham, Middleton \& Levine, 1992).

However, so far, few studies have combined the cellular automata algorithm with the design of toll plazas. Based on the modified NS model, we will establish an evaluation model to evaluate the performance of Asbury Park Toll Plaza in New Jersey, USA, and further optimize the design.

\section{Eval uation Model of Toll Plazas}

Before evaluating the performance of toll plazas, we should firstly introduce some relevant evaluation indexes to build the evaluation model of toll plazas. In this paper, through strict selections from various evaluation indexes, we finally select toll plaza's safety coefficient, throughput and cost as the main indexes of the evaluation model.

\subsection{Safety Coefficient of Toll Plazas}

The safety coefficient of toll plazas, is the quantification index of design's influence on the traffic accident rate. Gradient rate, is the ratio of the length of road expansion $(b)$ to the length of the gradient section $(L)$. When the gradient rate is small, the angle of the corner is small, which can bring less sense of deviation to drivers and decrease the accident rate. When the gradient rate is too large, drivers will have a stronger sense of deviation, which will increase the traffic accident rate. Therefore, to a great extent, the traffic accident rate is in proportion to the gradient rate of toll plazas.

The safety coefficient of toll plazas is related to traffic flow's average speed when entering and leaving the gradient section. The specific formula is as follows ( $\mathrm{Wu}, 2004)$ :

$$
K s=\frac{v}{v_{0}}=\frac{n l}{\frac{1}{n} \sum_{i=1}^{n} v_{0 i} \sum_{i=1}^{n} t_{i}}
$$

where, $n$ is the quantity of vehicles passing through the toll square during a period of time;

$l$ is the distance between the entrance and exit of the toll plaza;

$t_{i}$ is the cost time when the ith vehicle passes the toll plaza;

$v_{0 i}$ is the speed of the ith vehicle at the entrance of the toll plaza.

Meanwhile, the relationship between the value of $K s$ and the security degree of the toll square is shown in Table $1(\mathrm{Wu}, 2004)$ :

Table 1. Meaning of Different Ks values

\begin{tabular}{cc}
\hline The values of Ks & Toll Plaza security \\
\hline $0.8 \sim 1.0$ & Extremely secure \\
$0.6 \sim 0.8$ & Rather secure \\
$0.4 \sim 0.6$ & Rather insecure \\
$0 \sim 0.4$ & Extremely insecure \\
\hline
\end{tabular}

\subsection{Throughput of Toll Plazas}

The throughput of toll plazas, refers to the quantity of vehicles passing the toll plaza per hour. To calculate and determine throughput, we introduce a new traffic flow simulation model, which is furtherly optimized on Unidimensional N-S Traffic Flow Simulation Model based on CA (Cellular Automata) algorithm. 


\subsubsection{Cellular Automata Model}

Due to excellent effect that Unidimensional N-S Model has on traffic flow simulation, we furtherly revise its rules and summarize as the following new rules(Kong,2007):

(1) Acceleration Rule: In reality, drivers always expect to travel at the maximum speed within the specified range. If the speed of a vehicle does not reach the maximum speed, then its speed increases by 1 : $v_{n} \rightarrow \min \left(v_{n}+1, v_{\max }\right)$, where $v_{\max }$ is the maximum speed in a specified range. The following Figure 1 is the graphical representation of the Acceleration Rule, where the number besides cars represents the current speed.

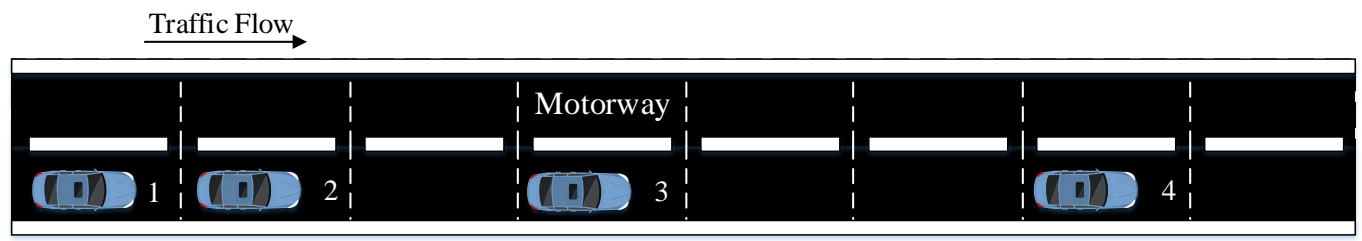

Figure 1. CA Acceleration Rule

(2) Non-Collision Rule: In order to avoid collisions with the front vehicle, if the speed of the vehicle exceeds the number of empty cells distance (the unit distance in CA algorithm) in front of itself, the vehicle's speed is forced to change as $v_{n} \rightarrow \min \left(v_{n}, d_{n}-1\right)$. In Figure 2 , due to its speed, the yellow car is forced to slow down to prevent collisions with the blue car in front of itself.

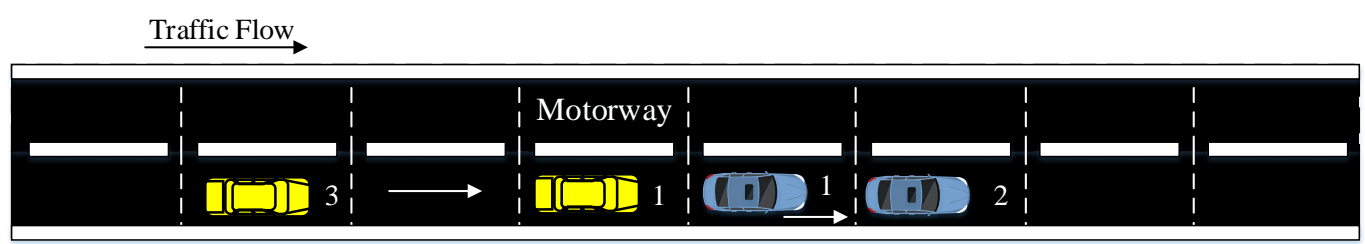

Figure 2. CA Non-Collision Rule

(3) Random Declaration Rule: in reality, there are lots of uncertain factors and drivers' overreaction, which will lead to vehicles' declaration. To simulate the situation above, we introduce Random Declaration Rule: if the speed of a vehicle exceeds 1 unit speed, then the vehicle will reduce by 1 unit speed with a low probability: $v_{n} \stackrel{P}{\longrightarrow} \max \left(v_{n}-1,0\right)$.Random Declaration is visually shown in Figure 3:

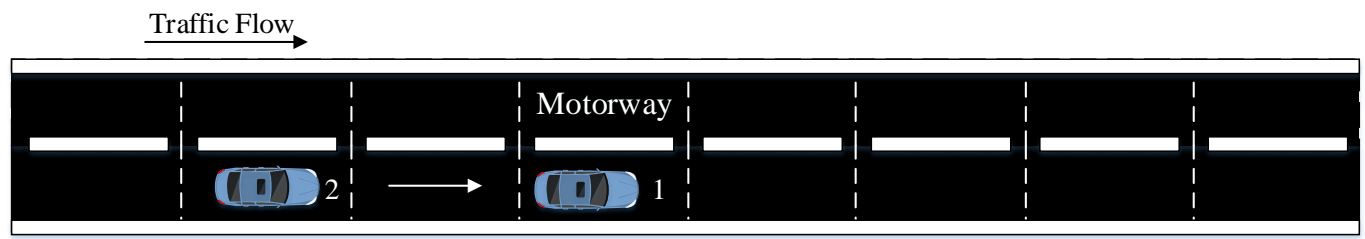

Figure 3. CA Random Deceleration Rule

(4) Location Update: The location of the vehicle follows the following rules: If the speed of a vehicle is $v_{n}$, the position is $x_{n}$, then the next position is: $x_{n}=x_{n}+v_{n}$.

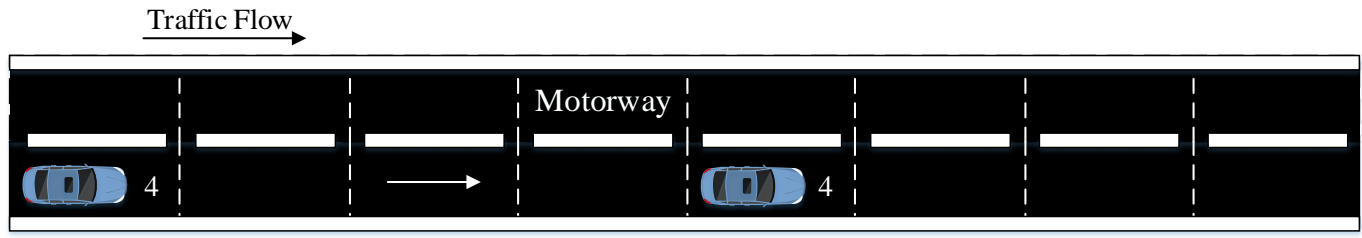

Figure 4. CA Location Update Rule 
(5) Changing-lane Rule: In order to simulate the two-dimensional traffic flow more realistically, we introduce Changing-lane Rule. This rule consists of two steps:

1) Preparation period:

If a car is following another one, then the back car meets with the prerequisites for changing lanes. Besides, the probability that the driver want to overtake should be considered.

2) Re-judgment period:

a. According to the traffic rules, the driver should give priority to change lane to the left when overtaking. If there are no other cars on the left of the car, then the driver can turn left.

b. If there are other cars on the left, then the driver should judge whether there are cars on the right side. If no cars, then the driver can change lanes to the right side.

c. If there are other cars existing on the both sides, then the driver fails to change lanes.

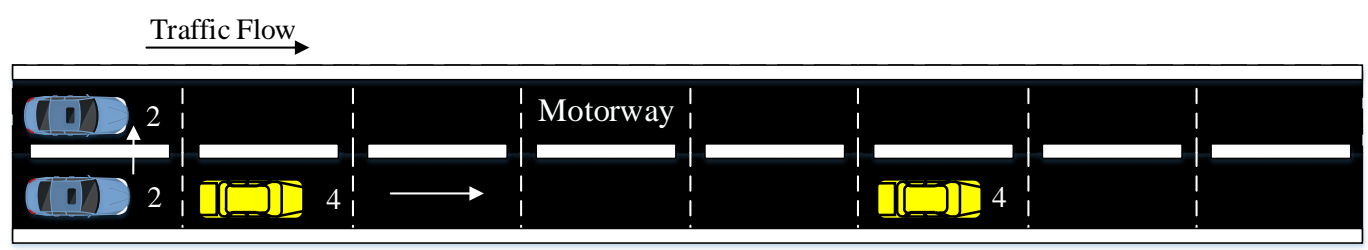

Figure 5. CA Changing-lane Rule

The Figure 5 shows that the blue car succeeds changing lanes to the left side.

\subsubsection{Simulation of Throughput}

In the process of simulating and calculating the throughput of specific toll plaza, we firstly need to get the shape parameters of geometric model of the toll plaza. Based on the abstract geometric model, we need to take advantage of CA algorithm to simulate the traffic flow. Finally, we can calculate the throughput. An example is given in Figure 6, where the vehicles traveling from left to right and there are 6 tollbooths in the middle of the toll plaza. Besides, $B$ represents the quantity of tollbooths and MergeFlux represents the simulation result of throughput.

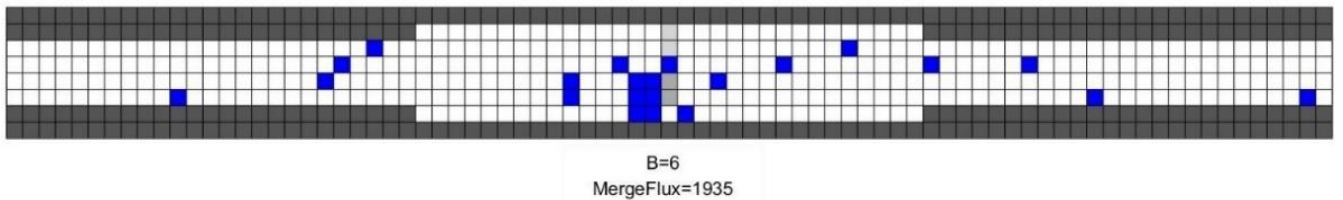

Figure 6. An Example of Traffic Flow Simulation

\subsubsection{Introduction of the Throughput Utilization Index}

While introducing the throughput, we furtherly introduce throughput utilization index, the ratio of the actual throughput to its maximum throughput, which, to a great extent, represents a rather important index measuring the performance of toll plazas. The specific formula is as follows:

$$
\eta=\frac{\text { throughput }_{\text {real }}}{\text { throughput }_{\max }}
$$

\subsection{Cost of Toll Plaza}

Considering the cost of the construction of toll plazas, we attribute main factors to two following points: the cost of the construction of tollbooths and expansion of the road. With further analysis, the former factor is related to the quantity of tollbooths and the latter one to the expansion area of the road.

For the cost of tollbooths, the main factor is the quantity of tollbooths. Therefore, we should set a reasonable number for the quantity of tollbooths with considering two requirements as follows: 
(1) On the one hand, considering the throughput and service efficiency, we should provide enough tollbooths.

(2) On the other hand, considering avoiding waste of resource, we need to restrict the quantity in a reasonable range.

For the cost of the expansion area of the road, we also take into account both requirement of local traffic situation and the cost.

In order to determine the reasonable quantity of tollbooths and to take into account the geometric characteristics of the toll plaza, we introduce the M/M/C model (Multi-queue and Multi-server Queuing Model) (Han, 2009). The following Figure 7 shows visually the model:

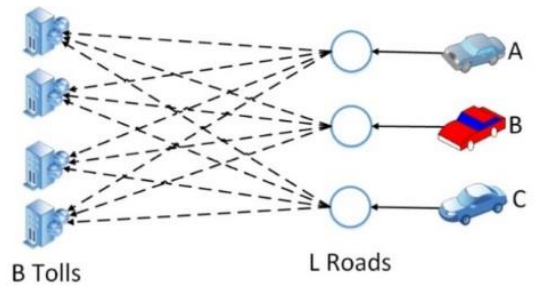

Figure 7. M/M/C Queuing Theory Model

Meanwhile, the main formulas of $\mathrm{M} / \mathrm{M} / \mathrm{C}$ model are as follows:

$$
\begin{aligned}
P_{0} & =\left[\sum_{k=0}^{c-1} \frac{1}{k !}\left(\frac{\lambda}{\mu}\right)^{k}+\frac{1}{c ! 1-\rho} \frac{1}{\mu}\left(\frac{\lambda}{\mu}\right)^{c}\right]^{-1} \\
L_{q} & =\frac{(c \rho)^{c} \rho}{c !(1-\rho)^{2}} P_{0} \\
\delta & =\frac{\rho}{c}, \rho=\frac{\lambda}{c \mu}
\end{aligned}
$$

where, $c$ is the quantity of tolls;

$\lambda$ is the average number of arriving vehicles per unit time;

$\mu$ is average service rate;

$\delta$ is traffic intensity;

$\rho$ is service intensity;

$L_{q}$ is the average queue length;

$P_{0}$ is the System State Probability of the initial time.

Based on the M/M/C model, we calculate the traffic intensity of each lane, which is corresponding to different

\begin{tabular}{|c|c|c|c|c|}
\hline $\begin{array}{ll} & \mathrm{Lq} / \mathrm{c} \\
\mathrm{c} & \end{array}$ & 0.5 & 1 & 1.5 & 2 \\
\hline 1 & 0.500 & 0.618 & 0.686 & 0.732 \\
\hline 2 & 0.657 & 0.755 & 0.806 & 0.839 \\
\hline 3 & 0.734 & 0.816 & 0.858 & 0.884 \\
\hline 4 & 0.781 & 0.852 & 0.887 & 0.909 \\
\hline 5 & 0.812 & 0.876 & 0.906 & 0.924 \\
\hline 6 & 0.835 & 0.893 & 0.919 & 0.935 \\
\hline 7 & 0.853 & 0.905 & 0.929 & 0.944 \\
\hline 8 & 0.867 & 0.915 & 0.937 & 0.950 \\
\hline
\end{tabular}
quantity of lanes and waiting vehicles. The results are shown in Table 2:

Table 2. Toll Plaza Traffic Intensity of Different Types of Highways

\section{Optimization Model of Toll Plazas' Design}

Before designing a new optimized toll plaza, we firstly introduce Asbury Park Toll Plaza as the preparation 
period for analysis, which is located in New Jersey, USA. Through furtherly analyzing the original design model, we optimize its geometric design to build a new optimized design model. Besides, by working with CA algorithm on MATLAB software platform, we will simulate and calculate the 3 main indexes of both original and optimized toll plaza design. Finally, we will compare the 3 indexes of both original and optimized design to confirm that our optimized design is preferable than the original one.

\subsection{Performance Analysis of Asbury Park Toll Plaza}

Based on the Google Maps platform, we measure the relevant parameters of the geometric model of Asbury Park Toll Plaza. Shown in Figure 8, Asbury Park Toll Plaza consists of 8 toll booths, 5 of which are equipped with ETC and 3 are MTC.

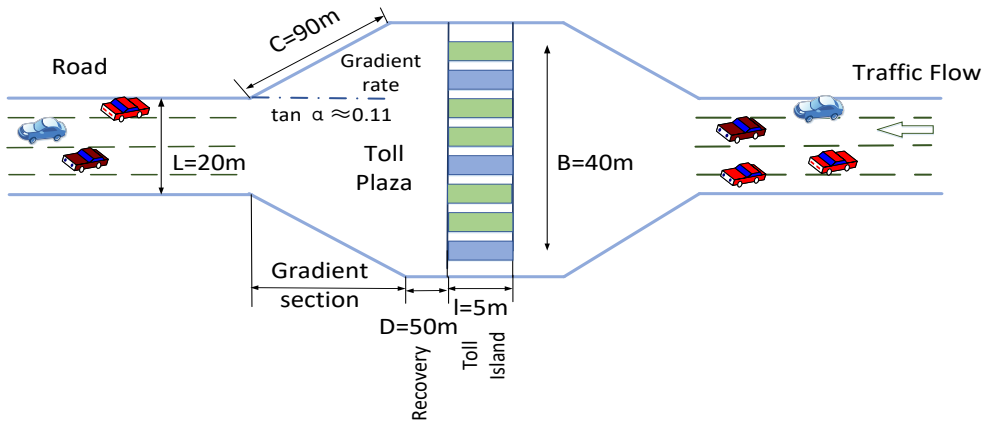

Figure 8. Asbury Park Toll Plaza Geometric Model

At the same time, by acquiring data from New Jersey Department of Transportation (NJDOT), we calculate the value of AADT (annual average daily traffic) of Asbury Park Toll Plaza: $A A D T=30125$ vehicle $/ \mathrm{h}$. According to the study from relevant scholars in USA, traffic volume should be measured by DHV (design hourly volume) ( $\mathrm{Su}, 2012)$. The specific formula is as follows:

$$
D H V=A A D T \times K \times D
$$

where, $K$ is DHV coefficient, with a standard value 0.12 ;

$D$ is coefficient of unbalanced distribution of direction, with a standard value 0.60 .

With the formula above, we can easily calculate that the traffic volume of Asbury Park Toll Plaza can be represented as $D H V=2169$ vehicles $/ \mathrm{h}$.

(1) Safety Coefficient

According to the Asbury Park Toll Plaza Geometric Model shown in Figure 8, we can easily determine that the gradient rate is 0.11 , which meets a reasonable range. Meanwhile, the lower the gradient rate is, the more reliable the toll plaza is. Furtherly, we calculate that the safety coefficient of Asbury Park Toll Plaza is 0.6875 .

(2) Throughput

Based on the Asbury Park Toll Plaza geometric model introduced above, we realize Unidimensional N-S Model on MATLAB software platform. With $D H V$ selected as the traffic volume index, we simulate and calculate the value of the throughput of Asbury Park Toll Plaza. The result is that when $D H V=2169$ vehicle/h then the throughput is about 2152 vehicle/h . Figure 9 is the simulation result.

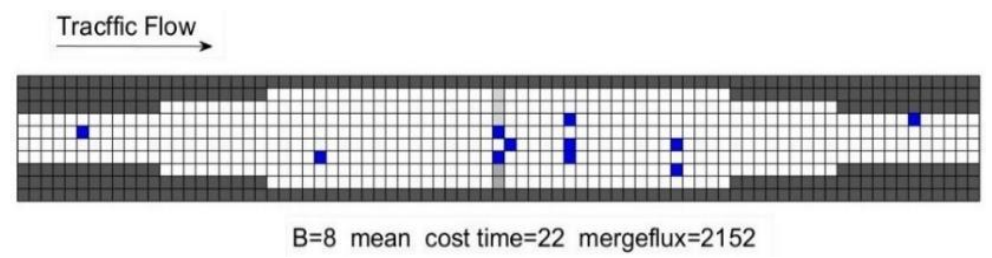

Figure 9. Simulation Result of Asbury Park Toll Plaza

In the meanwhile, in order to further explore the throughput utilization of Asbury Park Toll Plaza, we change the value of DHV to simulate and obtain different throughput results. Figure 9 shows the relationship between throughput and DHV: 


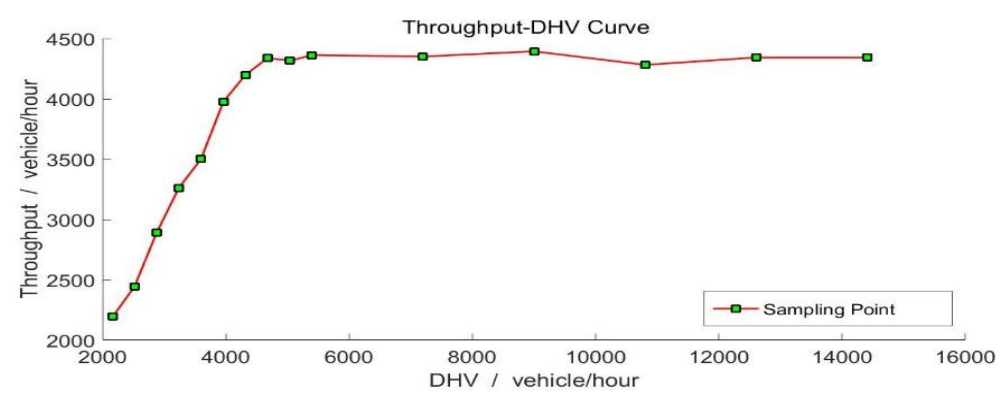

Figure 10. Throughput-DHV Curve

Based on Figure 10, we can calculate the throughput utilization:

(3) Cost

$$
\eta_{0}=\frac{\text { throughput }_{\text {real }}}{\text { throughput }_{\text {max }}} \approx 51.07 \%
$$

Based on the analysis of cost of toll plazas, the cost of Asbury Park Toll Plaza mainly includes the cost of the construction of tollbooths and expansion of the road. More importantly, the former factor is related to the quantity of tollbooths and the latter one to the expansion area of the road. Thus, according to specific parameters of the Asbury Park Toll Plaza geometric model, the quantity of tollbooths is 8 and the expansion area is 749.64 $\mathrm{m}^{2}$.

\subsection{Optimized Design Based on Asbury Park Toll Plaza}

Realizing an optimized design based on Asbury Park Toll Plaza, means that by changing the parameters of Asbury Park Toll Plaza geometric model, we need to further optimize the evaluation indexes of Asbury Park Toll Plaza: safety coefficient, throughput and cost.

(1) Optimization on Tollbooths' Cost Based on M/M/C Queuing Model

From the above, we can get the DHV: $D H V=2169$ vehicle $/ h$.Therefore, the traffic flow intensity should be calculated as follows:

$$
\lambda=\frac{D H V}{3600 s}=0.6025 \text { vehicle } / s
$$

Supposed that there are $s$ lanes needed and the traffic flow intensity of each lanes is $n_{s}$. Therefore, in theory, the maximum number of vehicles traveling on $B$ lanes per hour can be up to:

$$
N=B \times \frac{n_{s} \times 3600}{t}
$$

where, $t$ is the average service time of toll plaza.

From the Asbury Park Toll Plaza geometric model shown in Figure 8, there are 3 tollbooths equipped with MTC and 5 with ETC. What's more, the average service time of tollbooths equipped with MTC is $6 \mathrm{~s}$ per tollbooth and those with ETC is approximated as $0 \mathrm{~s}$. Therefore, we can easily calculate that $t=2.25 \mathrm{~s}$.

Taking into account the constraints of tollbooths: in theory, the quantity of vehicles that the toll plaza can serve ought to be larger than the actual traffic volume, DHV, we conclude as follows:

$$
N>D H V
$$

that is,

$$
B \times n_{s}>1.35
$$

On the one hand, owing to the fact that the quantity of main lanes of Asbury Park Toll Plaza is 4, there is a restriction: $B>L=4$. On the other hand, taking into account the fact that the cost should be reasonable, we ought to choose the minimum quantity of tollbooths under the restriction. Combining with the M/M/C queuing model and Table 2, we can optimize the quantity of tollbooths to the result: $B=6$. Also, the charging method can be optimized to the result: 3 for MTC and 3 for ETC. 


\section{(2) Optimization on Road Expansion's Cost}

Gradient rate of toll plazas, is mainly related to the cost of road expansion and safety coefficient. With analyzing Asbury Park Toll Plaza geometric model, we get that:

$$
D+\frac{B-L}{2 \tan \alpha}+\frac{l}{2} \geq s_{\text {limit }}
$$

where, $s_{\text {limit }}$ is the minimum distance from the midst of the toll plaza to the edge, and there are some relevant scholars studying and concluding that $s_{\text {limit }}=75 \mathrm{~m} \quad(\mathrm{Su}, 2012)$;

$D$ is the length of recovery;

$l$ is the width of tollbooths. As for Asbury Park Toll Plaza, $l=5 m$;

$B$ is the length of tollbooths;

$L$ is the number of lanes;

$\alpha$ is the gradual angel.

In order to make sure for higher safety coefficient of the design toll plaza, we restrict the range of $\alpha$.Wu pointed out in his master's thesis(Wu,2004) that the restriction of $\alpha$ is that $\arctan \frac{1}{10}<\alpha<\arctan \frac{1}{7}$.

In the meanwhile, we analyze Asbury Park Toll Plaza and obtain the relationship formula:

$$
\frac{1}{\text { tan } \alpha}+D_{\text {cell }} \geq 14.5
$$

where, $D_{\text {cell }}$ is the number of cells in CA algorithm corresponding to the length of the recovery.

In order to minimize the cost, we set $D_{\text {cell }}$ to its minimum. Then, the formula becomes:

$$
D_{\text {cell }}=\left\{\begin{array}{l}
0, \arctan \frac{1}{10} \leq \alpha \leq 0.069 \\
-\frac{1}{\tan \alpha}+14.5,0.069 \leq \alpha \leq \arctan \frac{1}{7}
\end{array}\right.
$$

Considering with Formula (11), we can get the relationship between road expansion area $S$ and gradual angel $\alpha$

$$
\begin{aligned}
& S=\left\{\begin{array}{l}
\frac{25}{\tan \alpha}+\frac{25}{2}, \arctan \frac{1}{10} \leq \alpha \leq 0.069 \\
750-\frac{25}{\tan \alpha}, 0.069 \leq \alpha \leq \arctan \frac{1}{7}
\end{array}\right. \\
& \text { s.t. } D_{\text {cell }}=0
\end{aligned}
$$

When $D=0$, the cost from road expansion is minimum. And the formula becomes:

$$
\left\{\begin{array}{l}
\alpha=0.069 \\
D_{\text {cell }}=0 \\
S=374
\end{array}\right.
$$

In conclusion, we can get the optimal value of gradual rate: $\tan \alpha \approx \alpha=0.069$.

Up to now, we confirm a new optimized design model for toll plaza. Figure 11 is the optimized model:

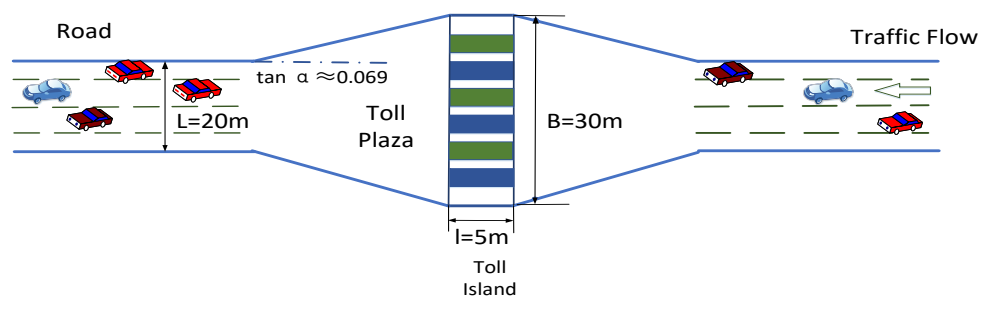

Figure 11. Optimized Toll Plaza Model 


\subsection{Comparative Analysis on the Evaluation Indexes of the Original and Designed Toll Plaza}

Based on CAalgorithm and M/M/C queuing model, we can analyze designed indexes of the optimized toll plaza and obtain its evaluation indexes value, including security coefficient, throughput and cost. The following Table 3 shows the situation of the comparison between indexes of Asbury Park Toll Plaza and designed toll plaza:

Table 3. Comparison between Toll Plaza \& Designed Toll Plaza

\begin{tabular}{|c|c|c|c|c|c|}
\hline \multirow[b]{2}{*}{$\begin{array}{l}\text { Evaluation Index } \\
\text { Toll Plaza } \\
\text { Type }\end{array}$} & \multirow[b]{2}{*}{$\begin{array}{l}\text { Safety } \\
\text { Degree }\end{array}$} & \multicolumn{2}{|c|}{ Throughput index } & \multicolumn{2}{|c|}{ Cost } \\
\hline & & $\begin{array}{c}\text { Throughput/ } \\
\text { vehicles } \cdot h^{-1}\end{array}$ & $\begin{array}{l}\text { Throughput } \\
\text { Utilization }\end{array}$ & $\begin{array}{c}\text { Toll } \\
\text { Numbers }\end{array}$ & $\begin{array}{c}\text { Road } \\
\text { Expansion } \\
\text { Area } / \mathrm{m}^{2}\end{array}$ \\
\hline $\begin{array}{c}\text { Asbury Park } \\
\text { Toll Plaza }\end{array}$ & 0.6857 & 2152 & $50.07 \%$ & 8 & 3918.18 \\
\hline $\begin{array}{l}\text { Designed } \\
\text { Toll Plaza }\end{array}$ & 0.986 & 2148 & $53.7 \%$ & 6 & 774.64 \\
\hline
\end{tabular}

Compared to Asbury Park Toll Plaza, the designed toll square model has been basically optimized in terms of safety coefficient, throughput or cost of the evaluation index system. In order to quantify the optimization result, we introduce the optimization proportion index, which is the ratio of the index of the optimized toll plaza to the index of Asbury Park Toll Plaza. The specific formula is as follows:

For the smaller the more optimized indicators:

$$
\eta_{\text {Optimization_Min }}=\frac{X_{\text {real }}-X_{\text {designed }}}{X_{\text {real }}} \times 100 \%
$$

For the larger the more optimized indicators:

$$
\eta_{\text {Optimization_Max }}=\frac{X_{\text {designed }}-X_{\text {real }}}{X_{\text {real }}} \times 100 \%
$$

where, $X_{\text {real }}$ is the index of Asbury Park Toll Plaza,

$X_{\text {designed }}$ is the index of designed toll plaza.

Besides, the smaller the more optimized indicators, include safety coefficient and throughput. The larger the more optimized indicators include cost. Based on the optimization proportion formula introduced above, the following specific optimization result is shown in Table 4:

Table 4. Optimization Proportion of the Designed Toll Plaza

\begin{tabular}{ccc|c|c|c}
\hline \multirow{2}{*}{ Evaluation Index } & Safety Degree & \multicolumn{2}{c}{ Throughput index } & \multicolumn{2}{c}{ Cost } \\
\cline { 3 - 6 } & Throughput & Throughput Utilization & $\begin{array}{c}\text { Toll } \\
\text { Numbers }\end{array}$ & Road Expansion Area \\
\hline $\begin{array}{c}\text { Optimization } \\
\text { Proportion }\end{array}$ & $+43.79 \%$ & $-0.19 \%$ & $+0.07 \%$ & $+25 \%$ & $+80.23 \%$ \\
\hline
\end{tabular}

In Table 4, '+' indicates that the index has been improved, while '-' indicates that the index has not been optimized. Analyzing from Table 4, we can see that the throughput is decreased by $0.19 \%$ and throughput utilization has been optimized by only $0.07 \%$. However, safety coefficient and cost are both greatly optimized: the former one is improved by $43.79 \%$ and the cost respectively, by $25 \%$ and $80.23 \%$. Therefore, generally speaking, compared to Asbury Park Toll Plaza, the evaluation indexes of designed toll plaza are greatly improved.

For the safety coefficient, we have:

$$
K s=\frac{v}{v_{0}}=\frac{n l}{\frac{1}{n} \sum_{i=1}^{n} v_{0 i} \sum_{i=1}^{n} t_{i}}
$$


as compared to the original Asbury Park Toll Plaza, the ${ }^{l}$ of designed toll plaza is much larger and the gradient rate is smaller. Consequently, on the one hand, we can easily conclude that $K s_{\text {real }}<K s_{\text {designed }}$ because of the $\operatorname{larger}^{l}$.On the other hand, owing to the fact that gradient rate is inversely proportional to the safety coefficient, the smaller gradient rate makes that the designed toll plaza safer. Therefore, the safety coefficient of the Asbury Park Toll Plaza is significantly improved.

For the throughput, analyzing from throughput-DHV curve in Figure 10, we can conclude that when DHV increases to a certain extent, the throughput will not continue to increase. Thus, throughput is related to DHV and throughput utilization is related to the design of the toll plaza. Besides, the DHV of the designed toll plaza is still consistent with the original Asbury Park Toll Plaza. Also, the geometric parameters of both model are almost the same. As a result, the throughput index of Asbury Park Toll Plaza and designed toll plaza are virtually the same.

For the cost, in virtue of further improvement, the cost of the designed model is further reduced not only in terms of the quantity of tollbooths, but also the area of expansion. Consequently, the cost of the original Asbury Park Toll Plaza should be further optimized.

\section{Robustness Anal ysis on the Designed Toll Plaza}

Based on the comparison of the original Asbury Park Toll Plaza and the designed toll plaza, we can draw a safe conclusion that compared with Asbury Park Toll Plaza, the evaluation indexes of designed toll plaza have been greatly improved. After design of the toll plaza, we further analyze the stability and robustness of the designed model from two aspects: traffic volume and traffic speed.

\subsection{Robustness Analysis on Traffic Flow}

On MATLAB software platform, we work with $\mathrm{CA}$ algorithm to simulate different situations which is differentiated by a series of different values of traffic volume. Based on the data from simulation, we can evaluate the service level and calculate $\mathrm{Lq}$ (the average queue length) of different situations. The following Figure 12 shows Service-Traffic Flow Curve and Lq-Traffic Flow Curve:
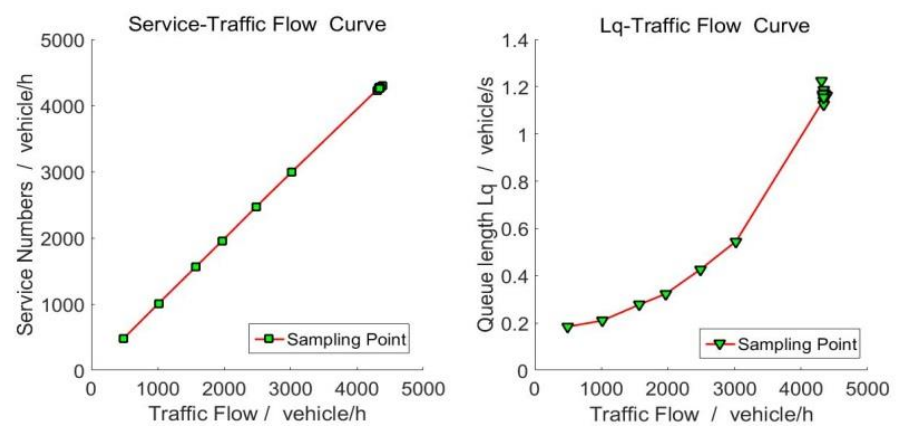

Figure 12. Robustness Analysis on Traffic Flow

Service level, is the average number of service vehicles per tollbooth per hour. Lq, is the average number of queuing vehicles per second. From the simulation result in Figure 12, we can find that the relationship between the service level and the traffic flow of the designed toll plaza is similar to direct proportion relationship, which means that the service level of the designed toll plaza will adapt to large traffic flow and there won't traffic jams phenomenon existing. As for Lq, with the increase in traffic flow, the average queue length is increasing. However, when the traffic flow continues to grow to a certain extent, Lq will increase slowly, which can avoid traffic jams phenomenon. In a word, when it comes to the robustness analysis of traffic flow, the designed toll plaza has an excellent performance and strong stability in different situations.

\subsection{Robustness Analysis on Maximum Speed of Traffic Flow}

In order to test the influence of different speed on the stability of the designed toll plaza, we work on MATLAB software platform. By changing the mathematical expectation of the probability distributions of traffic flow, we set the maximum speed of the traffic flow range to $18 \sim 180 \mathrm{~km} / \mathrm{h}$, simulating and obtaining a series of figures shown in Figure 13: 

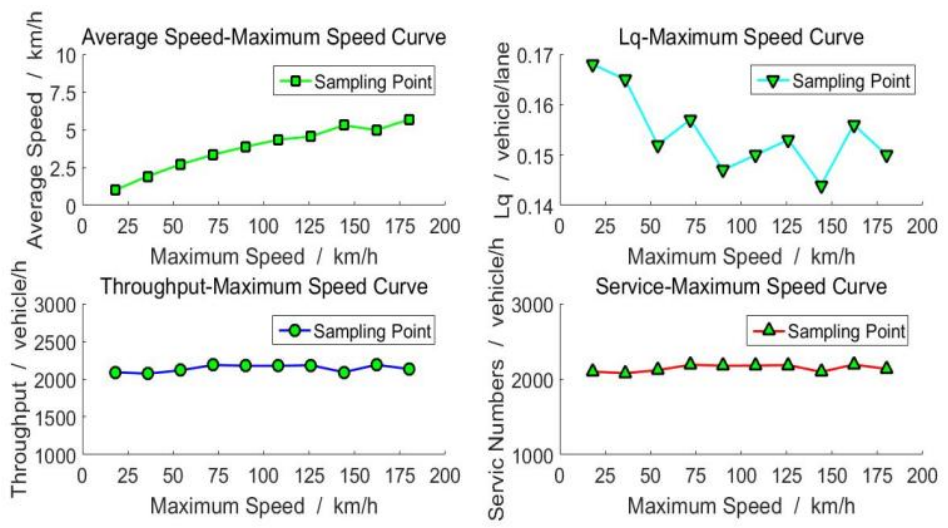

Figure 13. Robustness Analysis on Maximum Speed of Traffic Flow

Analyzing from Figure 13, we can safely draw following conclusions:

(1) As the maximum allowable speed increases, the average speed of traffic flow increases. When the maximum speed reach to about $144 \mathrm{~km} / \mathrm{h}$, the average speed begins to stabilize because the traveling vehicles are affected by the service level, traffic volume and the maximum speed.

(2) As the maximum allowable speed increases, the average queue length decreases. The simulation result shows that as the maximum speed increases, the congestion in the toll plaza is alleviated.

(3) As the maximum allowable speed increases, throughput does not change much. The simulation results show that the throughput of the toll plaza is not affected by the different speed of vehicles with the maximum speed of the traffic increases, so the throughput of the design model is relatively stable.

(4) With the increase in the maximum allowable speed, the throughput and the quantity of service vehicles have little significant changes. The simulation result shows that the service level of the designed toll plaza is quiet stable, indicating that the service ability of the toll plaza is strong enough to perfectly avoid the traffic jams phenomenon.

Therefore, by analyzing the robustness of the model from two aspects including the traffic flow and maximum speed of traffic flow, we testify that the designed model is more robust and various indexes perform more stable. In summary, compared with the original Asbury Park Toll Plaza, our designed toll plaza has been optimized in robustness and has a preferable performance in reality.

\section{Conclusion}

This paper first selected safety coefficient, throughput and cost as the evaluation indexes and established an evaluation model of the toll plaza. Then, we applied the modified N-S model of cellular automata to simulate the traffic flow in the Asbury Park Toll Plaza in New Jersey and obtained the corresponding indexes data. Furthermore, we optimized the design of Asbury Park Toll Plaza based on the M/M/C queuing theory and other methods mentioned above. Finally, we used the cellular automata algorithm to simulate the traffic flow situation again and made a comparative analysis of the original design and our design proposed in this paper. After comparative analysis, we found that our design plan was obviously better. Under the premise that the throughput index is not affected obviously, the safety coefficient is improved by $43.79 \%$, and the two sub indexes of cost are optimized by $25 \%$ and $80.23 \%$ respectively.

In this paper, we optimized the design plan for a toll plaza based on M/M/C queuing theory and cellular automata simulation algorithm. We can apply the optimization method to many areas of traffic flow simulation, such as simulation modeling of traffic flow under different traffic intensity and traffic situations. It is worth noting that the traffic flow simulation model established in this paper has a wide universality because the model can be applied to more areas of traffic flow simulation by changing the parameters of the algorithm and making some adjustments in the details.

In the future study, we will further refine the study of our model. For example, we will further improve the integrity and scientificity of the evaluation index system for toll plaza and make the calculation of cost more reasonable and practical. In addition, we will try different parameters for cellular automata so that simulation can be more practical. 


\section{References:}

Biham, O., Middleton, A. A., \& Levine, D. (1992). Self-organization and a dynamical transition in traffic-flow models. Physical Review A, 46(10), R6124. https://doi.org/10.1103/PhysRevA.46.R6124

Cremer, M., \& Ludwig, J. (1986). A fast simulation model for traffic flow on the basis of Boolean $\begin{array}{llll}\text { operations. Mathematics and Computers in } & \text { 297-303. }\end{array}$ http://dx.doi.org/10.1016/0378-4754(86)90051-0

Daniel, Gerlaugh, Ma, Huber, X., \& Jiang, H. (1983). Traffic Flow Theory. China Communications Press.

Han, Z. G. (2009). Methods and Applications of Mathematical Modeling. Higher Education Press

Komada, K., Masukura, S., \& Nagatani, T. (2009). Traffic flow on a toll highway with electronic and traditional tollgates. Physica A: Statistical Mechanics and its Applications, 388(24), 4979-4990. http://dx.doi.org/10.1016/j.physa.2009.08.019

Kong, X. J.(2007). Research on Modelling and Characteristics Analysis of traffic Flow Based on Cellular Automaton (Doctoral dissertation, Doctor]. Beijing: Beijing Jiaotong University).

Li, J. (1991). Japan highway design essentials.

Nagel, K., \& Schreckenberg, M. (1992). A cellular automaton model for freeway traffic. Journal de physique I, 2(12), 2221-2229. https://doi.org/10.1051/jp1:1992277

Perry, R. F., \& Gupta, S. M. (2001). Response surface methodology applied to toll plaza design for the transition to electronic toll collection. International Transactions in Operational Research,8(6), 707-726. http://dx.doi.org/10.1111/1475-3995.t01-1-00333

Schaufler, A. E. (1997). Toll plaza design (Vol. 240). Transportation Research Board.

Su, L. (2012). Study on the design of highwaytoll station [D] (Doctoral dissertation, Chang'an University).

Van Dijk, N. M., Hermans, M. D., Teunisse, M. J., \& Schuurman, H. (1999). Designing the Westerscheldetunnel toll plaza using a combination of queueing and simulation. In Simulation Conference Proceedings, 1999 Winter (Vol. 2, pp. 1272-1279). IEEE.https://doi.org/10.1109/WSC.1999.816853

Wu, X. W. (2004). Highway toll station traffic safety research (Doctoral dissertation, Xi'an: Chang'an University [master's thesis]).

Zhang, M., Chen, H., \& Wu, X. W. (2009). Safety Evaluation Model of Freeway Toll Station. China Safety Science Journal, (10), 139-144. http://dx.chinadoi.cn/10.3969/j.issn.1003-3033.2009.10.024

Zhang, N. (2015). Research on the key design parameters of main toll station based on alleviate congestion (Master's thesis, Hebei University of Technology).

Zhang, X. Q., Wang, Y., \& Hu, Q. H. (2014). Research and simulation on cellular automaton model of mixed traffic flow at intersection. Acta Physica Sinica, 63(1), 0105-0105. https://doi.org/10.7498/aps.63.010508

\section{Copyrights}

Copyright for this article is retained by the author(s), with first publication rights granted to the journal.

This is an open-access article distributed under the terms and conditions of the Creative Commons Attribution license (http://creativecommons.org/licenses/by/4.0/). 